\title{
Apigenin Exerts Anti-inflammatory Effects in an Experimental Model of Acute Pancreatitis by Down-regulating TNF- $\alpha$
}

\author{
ALEXANDROS CHARALABOPOULOS ${ }^{1,2^{*}}$, SPYRIDON DAVAKIS ${ }^{1,3}$, MARIA LAMBROPOULOU ${ }^{4}$, \\ APOSTOLOS PAPALOIS $^{2}$, CONSTANTINOS SIMOPOULOS ${ }^{5}$ and ALEXANDRA TSAROUCHA ${ }^{5}$ \\ ${ }^{1}$ Department of Upper Gastrointestinal and General Surgery, \\ Broomfield Hospital, Mid Essex Hospital Services NHS Trust, Essex, U.K.; \\ ${ }^{2}$ Experimental-Research Center, ELPEN Pharmaceuticals, Athens, Greece; \\ ${ }^{3}$ First Department of Surgery, Laiko General Hospital, \\ National and Kapodistrian University of Athens, Athens, Greece; \\ ${ }^{4}$ Department of Histopathology, Faculty of Medicine, Democritus University of Thrace, Alexandroupoli, Greece; \\ ${ }^{5}$ Laboratory of Experimental Surgery and Surgical Research, \\ Faculty of Medicine, Democritus University of Thrace, Alexandroupoli, Greece
}

\begin{abstract}
Background/Aim: This study investigated the anti-inflammatory effect of apigenin in an experimental model of acute pancreatitis. Inflammatory response was reflected by tissue expression of the cytokine TNF- $\alpha$ coupled with histological examination. Materials and Methods: Wistar rats were divided into three groups: Sham-group animals underwent laparotomy only, without any other interventions. Control-group animals underwent laparotomy and bilio-pancreatic duct ligation to induce pancreatitis without apigenin administration. Apigenin group animals were further treated with apigenin. Euthanasia was performed at 6, 12, 24, 48 and $72 \mathrm{~h}$ post-operatively. Results: Over-expression of TNF- $\alpha$ in relation to postoperative time was observed in the control group $(p<0.001)$. In the apigenin group, under-expression of $T N F-\alpha$ in relation to postoperative time was observed $(p<0.013)$. At $72 h$, apigenin reduced pancreatic TNF- $\alpha$ expression and prevented pancreatic necrosis. Conclusion: Apigenin slows progression and reduces severity of acute pancreatitis. Apigenin may serve as an adjunct to a more successful therapeutic strategy in acute pancreatitis.
\end{abstract}

This article is freely accessible online.

Correspondence to: Spyridon Davakis, MD, General Surgery Registrar, Department of Upper Gastrointestinal and General Surgery, Laiko General Hospital, National and Kapodistrian University of Athens, Agiou Thoma 17 Str., 11527, Athens, Greece. Tel: +44 07553104746, +30 6973762451, e-mail: spdavakis@gmail.com

Key Words: Apigenin, TNF- $\alpha$, acute pancreatitis, biliopancreatic duct ligation.
The anti-inflammatory, the anti-oxidative and the anticarcinogenic role of the fruit-, vegetable- and plant-derived flavonoid apigenin has been well established (1). Apigenin and other flavonoids are targeting TNF- $\alpha$ by either suppressing its production or by inhibiting its function. TNF- $\alpha$ dysfunction or overproduction, can lead to development of chronic inflammatory diseases and cancer, via activation of the nuclear factor-kappa $\mathrm{B}(\mathrm{NF}-\mathrm{kB})$. This is achieved by ligation to the transmembrane TNF- $\alpha$ receptor, which stimulates cellular pathways leading to activation of IkB $\alpha$ kinase (IKK) (2). In addition, the anti-inflammatory role of apigenin, is partly explained by the direct inhibition of TNF- $\alpha$ gene expression. Moreover, it inhibits NF-kB action, via inhibition of nuclear transposition of $\mathrm{p} 65$. The latter results in deactivation of nitric oxide synthetase (NOS) and cycloxygenase-2 (COX-2) genes, thus playing a vital role in suppressing inflammatory process and in cell-cycle arrest (3). Thus, apigenin by targeting and down-regulating TNF- $\alpha$ and NF-kB, has been shown to play a pivotal role in the inflammatory process (4-6).

Acute pancreatitis is characterized as acute inflammation of the pancreas with variable involvement of other tissues or distant organs/systems. Its clinical course is mostly benign and clinical manifestations improve progressively within the first few days. Two distinct clinical entities have been identified; first, acute mild pancreatitis, which is the commonest, is related to minimal organ dysfunction and uneventful recovery, and second, acute severe pancreatitis is present in about $20 \%$ of cases and is related to distant organ/system dysfunction with or without local pancreatic complications like pancreatic abscess, pseudocyst or necrosis with the latter being mainly related to episode severity (7, 8). Mortality associated with acute pancreatitis is observed 
in about $10 \%$ of cases and half of those occur within the first two weeks from symptom onset and are attributed to shock and multiorgan failure. The rest occur later, typically after the first four weeks and are due to septic complications (9). Despite current advances, the management of acute pancreatitis remains mainly supportive and not causative, with pancreatic inflammation that initiates the disease's vicious circle, not being addressed. Up to date, there is no drug to prevent or treat the condition. Improved clinical outcomes are mostly due to continuous advancement of various supportive treatments. Effective measures are centered on the management of septic complications like biliary sepsis, pancreatic necrosis and pseudocyst, which are accountable for more than $50 \%$ to $80 \%$ of mortality $(10,11)$.

Although the exact mechanisms that initiate an episode of acute pancreatitis are not clearly understood, once initiated they share the same inflammatory and repair pathways (12). Three distinct steps are thought to play a pivotal role in the pathogenesis and progression of acute pancreatitis, injury of pancreatic acinar cells, local, and systemic inflammation. Acinar cell damage provokes leukocyte pooling in the peripancreatic vascular network and within a few hours, activated monocytes are attracted, which further stimulate the inflammatory response through production of proinflammatory cytokines. The observed cytokine disequilibrium provokes activation of the complement system resulting in the release of factor $\mathrm{C} 5 \mathrm{a}$, which in turn stimulates further aggregation of macrophages and neutrophils. These events lead to additional pro- and antiinflammatory cytokine production via transcriptional factors like $\mathrm{NF-kB}$, and their release (13). This cytokine release not only increases capillary permeability in the pancreatic microcirculation, but also provokes pancreatic necrosis due to thrombosis and haemorrhage within the pancreatic tissue $(14,15)$. In turn, local and systemic hyper-production of proinflammatory cytokines like, tumor necrosis factor alpha (TNF- $\alpha$ ), interleukins, nitric oxide, complement system components, platelet activating factor, free radicals and other macrophage and neutrophil secretory products takes place (16). Additionally, expression of endothelial adhesion molecules like VCAM-1 (vascular cell adhesion molecule-1) is stimulated by pancreatic acinar cell injury and further augments the inflammatory response. This leads to a vicious circle that affects the systemic vascular endothelium leading to vasodilation, increased capillary permeability and interstitial edema (17).

In this cascade of events, TNF- $\alpha$ plays an important role in the genesis, as well as in the evolution of acute pancreatitis episodes. It is known that TNF- $\alpha$ levels increase during the initiation and progression phase of acute pancreatitis. As a result, TNF- $\alpha$ activity is neutralized and acts as an anti-inflammatory mediator (18). Intrapancreatic TNF- $\alpha$ levels are traceable about $1 \mathrm{~h}$ from pancreatitis onset and continue to rapidly increase in the following $6 \mathrm{~h}$ (18). Administration of TNF- $\alpha$ alone or in conjunction with another pro-inflammatory cytokine, interleukin- $1 \alpha$, seems to augment the inflammatory process during acute pancreatitis in rats. The same phenomenon is also observed in mutant rats lacking TNF receptors (19). Furthermore, anti-TNF- $\alpha$ antibodies have been used in experimental models of acute pancreatitis and their use seems to moderate the severity of the acute edematous and necrotising pancreatitis episodes (20-24).

Studies at the initiation of the inflammatory process during acute pancreatitis are difficult to perform in humans. This is mainly due to late diagnosis when pancreatic injury has already been established as well as to lack of pancreatic tissue for histopathological evaluation at these early stages. Consequently, animal models of acute pancreatitis are used to study the disease pathophysiology, course and treatment. In our study, in order to reproduce the commonest cause of pancreatitis in humans, gallstone pancreatitis, a rat model of acute obstructive pancreatitis was created by para-duodenal ligation of the common bilio-pancreatic duct. This is a low cost, easily reproducible experimental model of acute pancreatitis that does not require significant surgical dexterity and is well established in the literature as a model of acute severe pancreatitis $(25,26)$.

Despite the beneficial actions of apigenin in inflammation, its beneficial role in preventing or improving the course of acute pancreatitis remains vastly unexplored (27). This is one of the very few studies on apigenin and its role in acute pancreatitis and the first that correlates apigenin with TNF- $\alpha$ expression (28). We aim to investigate apigenin's role in the inflammatory process during acute pancreatitis by quantifying TNF- $\alpha$ expression and histologically evaluating the changes on the pancreatic parenchyma.

\section{Materials and Methods}

Experimental animals. Three to four months old male wistar rats with a median weight of $330 \mathrm{~g}(\mathrm{IQR}=225-470 \mathrm{~g})$ were provided by the 'Pasteur Institute' with the experiments taking place at the approved experimental research centre of 'ELPEN' in Athens, Greece. All animals were maintained in polycarbonate cages of four, under conventional environmental conditions of temperature (22$25^{\circ} \mathrm{C}$ ), humidity (55\%-58\%) and lighting (12 h light $/ 12 \mathrm{~h}$ dark), with free access at will to food and water. The experimental procedures conform to National Research Council Guide for the Care and Use of Laboratory Animals and Directive 86/609 of the European Union, protocol number K/2284.

Study design. Animals were randomly assigned into 3 groups. In the sham group (S), healthy animals underwent midline laparotomy without bilio-pancreatic duct ligation that induces pancreatitis and without administration of apigenin. A total of 20 animals formed 5 groups of 4 according to euthanasia time at 6,12, 24, 48 and $72 \mathrm{~h}$ (groups S6, S12, S24, S48, S72 respectively). In the control group 
(C), 50 animals underwent midline laparotomy without induction of pancreatitis via ligation of the bilio-pancreatic duct and without administration of apigenin. They were subdivided into five groups of 10 animals according to euthanasia time, i.e., $6 \mathrm{~h}$ (C6), $12 \mathrm{~h}$ (C12), $24 \mathrm{~h}(\mathrm{C} 24), 48 \mathrm{~h}(\mathrm{C} 48)$ and $72 \mathrm{~h}(\mathrm{C} 72)$. In the apigenin group (AP), $(n=50)$ animals underwent midline laparotomy, induction of pancreatitis via ligation of the bilio-pancreatic duct, and apigenin administration as follows: a) group AP6: 10 animals, 1 dose of 4 $\mathrm{ml}$, euthanasia at $6 \mathrm{~h}$; b) AP12: 10 animals, 1 dose of $4 \mathrm{ml}$, euthanasia at $12 \mathrm{~h}$; c) AP24: 10 animals, 1 dose of $4 \mathrm{ml}$, euthanasia at $24 \mathrm{~h}$; d) AP48: 10 animals, 2 doses of $4 \mathrm{ml}$ with a $24 \mathrm{~h}$ interval, euthanasia at $48 \mathrm{~h}$; e) AP72: 10 animals, 3 doses of $4 \mathrm{ml}$ with $24 \mathrm{~h}$ intervals, euthanasia at $72 \mathrm{~h}$. The overall study design was based on a previous publication by members of our research group (23).

The test of probability in this study for type I error was set at nominal significance level of $a=0.05$ and the power of the tests was set at $0.80(80 \%)$ (b-probability of type II) as a standard for adequacy. A sample size of $n=50$ in each group ( $C$ versus AP) revealed an $87 \%$ chance of accurate prediction.

Apigenin preparation and administration. Apigenin is sparingly soluble and was diluted into a solution according to established methodology so as to aid with its enteral absorption $(28,29)$. The solution was prepared by dissolving $660 \mathrm{mg}$ of apigenin (Sigma Life Science, Taufkirchen, Germany) in $500 \mathrm{ml}$ of corn oil and subsequently adding $2 \mathrm{ml}$ of dimethyl sulfoxide (DMSO) and $10 \mathrm{ml}$ of Tween 80 . The final concentration was $5 \mathrm{mg}$ of apigenin in $4 \mathrm{ml}$ solution. This dosage was based on previous studies on estimated oral intake of food flavonoids (30).

The solution was administered, through an 8 Fr nasogastric catheter and after full recovery of the animal in order to prevent aspiration. The administration intervals were chosen by the authors so as to regularly assess the exerted effect of apigenin on TNF- $\alpha$ during the first $72 \mathrm{~h}$, when it is known that apigenin concentration in the body reaches its peak (29).

Anesthesia and operative technique. Induction to anesthesia was achieved by placing the animal in a specially designed glass cage connected to isoflurane supply, following a $0.25 \mathrm{ml}(10 \mathrm{mg} / \mathrm{ml})$ subcutaneous injection of the opioid butorphanol as analgesic (Dolorex; Intervet, Schering-Plough Animal Health, Boxmeer, Holland). Two to three minutes later, anesthesia was confirmed by the lack of swallowing movements, loss of tail flick reflex, immobility and ptosis of the animal. Then, the animal was placed on the operating board and endotracheal intubation under direct laryngoscopy was performed via a $16 \mathrm{Fr}$ venous catheter.

While endotracheal intubation may not be necessary to acquire animal ventilation, it was the conventional ventilation method in our study groups. Although rat experiments can be performed via usage of rat face-mask or ketamine alone, endotracheal intubation was preferred as it provides conditions of controlled mechanical ventilation and is recommended by most researchers (31).

The endotracheal catheter was directly connected to an UgoBasile rodent ventilator (Harvard Apparatus, Holliston, MA, USA) at the following settings: tidal volume: $3 \mathrm{ml}$; rate: 70 breaths $/ \mathrm{min}$. Proper intubation was confirmed by chest expansion and lung auscultation. Maintenance of anesthesia was accomplished using a mixture of $93 \% \mathrm{O}_{2}, 5 \% \mathrm{CO}_{2}$, and $2 \%$ isoflurane. On the operating board, the animal was placed in a supine position and was immobilized by wrapping its limbs with adhesive tape and stabilizing its mandible with an elastic string. The endotracheal tube and the anesthetic gas tubing system were stabilized by adhesive tapes. The abdominal hair was shaved and the skin was treated with $10 \%$ povidone iodine. Midline laparotomy from the xiphoid process and for $3 \mathrm{~cm}$ caudally was performed with scissor-incision of the linea alba. The abdominal cavity was then entered and the duodenal loop was isolated. At its medial aspect the bilio-pancreatic duct was identified. Paraduodenal ligation of the duct with non-absorbable $4 / 0$ silk suture was performed and acute pancreatitis was thus induced; the latter operating step was performed in the control and apigenin groups. The organs were returned to their anatomical position and $1 \mathrm{ml}$ normal saline together with $1 \mathrm{ml} 5 \%$ dextrose were instilled intra-abdominally. Linea alba was approximated with $3 / 0$ Vicryl and skin with 3/0 Nylon sutures.

At laparotomy closure, isoflurane was discontinued and only oxygen was administered. A minute following closure and once spontaneous breathing movements were noticed, the animal was extubated and turned to its side preventing aspiration. Full recovery was established and the animal was returned to its cage when fully mobile. Operating time was between 10-15 min in all cases. Postoperatively, animals were fed ad libitum while systemic analgesia with butorphanol ( $2 \mathrm{mg} / \mathrm{kg}$ subcutaneously), initially four doses hourly and then depending on the animal's response as judged by its mobility and eating drive, was administered. In the sham group, the experiments were terminated without the duct ligation step. Soon after laparotomy, the pancreas was identified and mobilized and no further steps were taken until closure of the abdominal cavity. In the apigenin group and post-operatively, $4 \mathrm{ml}$ apigenin solution was administered orally according to protocol.

Euthanasia and tissue sampling. The animals were sacrificed according to protocol on predetermined time. A mixture of 0.3-0.6 ml ketamine (Narcetan; Vetoquinol, Buckingham, UK) and 0.1-0.3 ml xylazine (Rompun; Bayer, Uxbridge, UK) up to three doses was used. Re-laparotomy was performed, animals were exsanguinated and pancreatic tissue was harvested. Specimens were placed in $10 \%$ neutral buffered formalin solution and were sent for histological evaluation and TNF- $\alpha$ immunohistochemical staining.

Histological evaluation, immunohistochemistry and TNF-a expression. Histological examination was performed in hematoxylin-eosin stained slides. Five parameters were evaluated on each case: hemorrhage, duct dilatation, edema, acinar necrosis and inflammatory infiltration. Results for each parameter were quantified according to a scoring system that ranged from absence of changes to severe lesions ( 0 : none, 1: mild, 2: moderate, 3: severe) (Figure 1). Histological scoring was accomplished according to a modified Sidhu's scoring system $(28,32)$. The scores of each parameter ineach slide were added to obtain the histopathologic score. Immunohistochemistry was performed using the biotin/streptavidin technique and the HRP-En Vision kit, Mouse/Rabbit detection system (DAKO, Netherlands) (33). The antibody used for the detection of TNF- $\alpha$, was the rabbit TNF $\alpha$ polyclonal PAB8016 antibody in 1:1,000 dilution (ABNOVA, Germany). Scoring was assigned according to the proportion of cells with cytoplasmic staining. Sections with greater than $10 \%$ stained cells were considered as being positive (0: negative; 1 : mild; 2 : moderate; and 3: intense expression). The positive expression of TNF- $\alpha$ was determined by counting the number of stained cells. The average labeling index of TNF- $\alpha$ was assessed according to the 
proportion of positive cells after scanning the entire section of the specimen. TNF- $\alpha$ expression was graded as negative $(0)$ for $<10 \%$ of stained cells, mild $(+)$ for $10 \%-30 \%$ of stained cells, moderate $(++)$ for $30 \%-70 \%$ stained cells, and intense $(+++)$ for $>70 \%$ stained cells (Figure 2).

Statistical analysis. Data were analyzed with the use of Stata statistical package version 14 for windows (Stata Corp, College Station, TX, USA). For evaluation of pancreatic TNF- $\alpha$ expression, as well as for histopathological parameters of acute pancreatitis based on postoperative times and separately for each group, the nonparametric Kendall's rank correlation coefficient was utilized (Kendall's tau) (index of measuring tendency). Kendall's tau varies from -1 to +1 . Negative values state negative correlation, positive values state positive correlation, while nought value states independence of the correlated parameters. The statistical evaluation between TNF- $\alpha$ expression in the rat pancreas as well as for the histopathological parameters of acute pancreatitis in each animal group, for given postoperative times, was based on Pearson's chisquared test. The statistically significant level used, was at $p$-value of $0.05(p<0.05)$.

\section{Results}

A total of 120 wistar rats were included in the study. Animals were randomly assigned, without compromising statistical power (34). Two animals from the sham group and one from the apigenin group died few hours before the $24 \mathrm{~h}$ euthanasia time. For homogeneity reasons and to avoid skewing of results, these animals were not included in the statistical analysis.

Sham group. In this group and as expected since pancreatitis was not induced, there was no significant difference of TNF$\alpha$ expression based on postoperative time $(p=0.597$, Kendall's tau=-0.120) (Figure 3, Table I). For the histopathological parameters studied there was no significant difference apart from duct dilatation, where significant decremental tendency was observed $(p=0.015$, Kendall's tau=-0.640) (Figure 1A, Table I).

Control group. As the postoperative time was increasing, a significant difference in TNF- $\alpha$ expression was observed in the rat pancreas $(p<0.001$, Kendall's tau=0.742) (Figure 3, Table I). In detail, in the subgroup C6, mild (+) and moderate (++) TNF- $\alpha$ expression was seen in $90 \%$ and $10 \%$ of animals, respectively. Intense (+++) TNF- $\alpha$ expression was not observed. In the subgroup C72, all animals (100\%) showed intense $(+++)$ pancreatic TNF- $\alpha$ expression (Figure $2 \mathrm{C})$. Furthermore, and based on time, significant differences were observed for haemmorhage $(p<0.001$, Kendall's tau=0.424), duct dilatation $(p<0.001$, Kendall's tau=0.616), edema $(p<0.001$, Kendall's tau=0.861), acinar necrosis $(p<0.001$, Kendall's tau=0.697) and inflammatory infiltration $(p<0.001$, Kendall's tau=0.627) (Figure 1C, D, Table I). Specifically, pancreatic necrosis was not observed in the C6 subgroup but was present in all (100\%) animals of the C72 subgroup. So, with time progression, both TNF- $\alpha$ expression as well as all five histological parameters studied, showed significant changes that reflect the severity of pancreatitis in this group.

Apigenin group. In this study group, in contrast to the control group, at any given time only mild $(+)$ or moderate $(++)$ but not intense (+++) TNF- $\alpha$ expression was observed. Overall, with time progression a significant difference of TNF- $\alpha$ expression was noticed ( $p=0.013$, Kendall's tau=-0.405) (Figure 3, Table I). Furthermore, TNF- $\alpha$ expression in rat pancreas was becoming appreciably milder as can be seen by subgroup analysis; while in subgroup AP6,60\% of the animals showed moderate (++) and $40 \%$ showed mild (+) TNF- $\alpha$ expression, in subgroup AP72, all animals (100\%) showed only mild (+) TNF- $\alpha$ expression (Figure 2A, B). Regarding the 5 histologic parameters studied, while a significant difference was observed for haemmorhage $(p=0.004$, Kendall's tau $=0.286)$, duct dilatation $(p=0.005$, Kendall's tau $=0.387)$ and edema $(p<0.001$, Kendall's tau=0.706), no statistically significant difference was observed regarding pancreatic necrosis and inflammatory infiltration (Figure 1B). For the latter parameter, a statistically incremental tendency was only observed $(p=0.073$, Kendall's tau=0.210) (Table I). In comparison to the control group, administration of apigenin exerted a beneficial role in acute pancreatitis; it's effect especially on reducing episode severity by reducing pancreatic necrosis became easily evident; while at $72 \mathrm{~h}$, all animals (100\%) in the control group developed pancreatic necrosis, in the apigenin group no necrosis (0\%) was seen (Table I). Moreover, its beneficial action is further extrapolated by the reduced expression of TNF- $\alpha$ (Figure 3, Table I).

Effect of apigenin at prolonged euthanasia time. As apigenin exerts its beneficial effect, variability in pancreatic TNF- $\alpha$ expression in the control and apigenin groups, is most likely to be pronounced at prolonged postoperative times. At $72 \mathrm{~h}$, there was a significant differentiation between TNF- $\alpha$ expression in different subgroups $(p<0.001)$ (Table I). Specifically, all animals with acute pancreatitis and without apigenin administration (control group), showed intense expression of TNF- $\alpha$, while animals in the apigenin group showed mild TNF-a expression $(p<0.001)$ (Figure 3$)$. As expected, rats without acute pancreatitis (sham group), mostly showed absence of pathological changes, like pancreatic haemmorhage and edema $(\mathrm{p} \leq 0.001)$ (Table I). On the contrary, at $72 \mathrm{~h}$, and in comparison to the apigenin group, the majority of rats with pancreatitis and no apigenin administration (control group) showed more severe pathological changes like duct dilatation, acinar necrosis and inflammatory infiltration $(p<0.001)$ (Table I). 


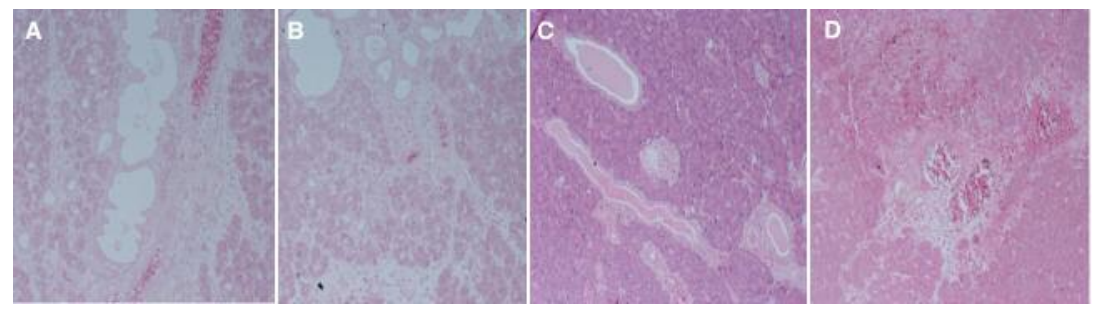

Figure 1. Characteristic Hematoxylin \& Eosin stained sections of the pancreas of rats with acute pancreatitis. A: Absence-(0) of lesions. Hemorrhage score 0. Duct dilatation score 0. Edema score 0. Acinar necrosis score 0. Inflammatory infiltration score 0. (×100). B: Mild-(1) degree lesions. Hemorrhage score 1. Duct dilatation score 1. Edema score 1. Acinar necrosis score 1. (×100). C: Moderate-(2) degree lesions. Duct dilatation score 2. (×100). D: Severe-(3) degree lesions. Inflammatory infiltration score 3. (×100).

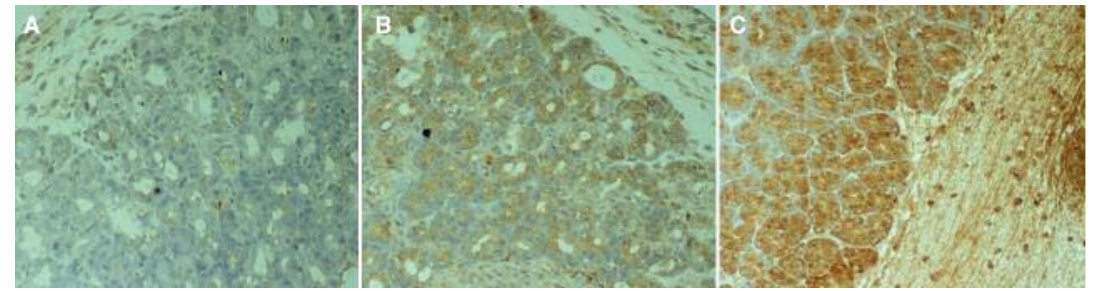

Figure 2. Characteristic sections of the pancreas of rats with acute pancreatitis immunocytochemically stained with biotin-streptavidin technique for evaluation of TNF- $\alpha$ expression. The TNF-a/antibody complex is stained brown. A: Mild (+) TNF- $\alpha$ expression. $(\times 200)$. B: Moderate (++) TNF- $\alpha$ expression. $(\times 200) . C$ : Intense $(+++)$ TNF- $\alpha$ expression. $(\times 200)$.

\section{Discussion}

It is well established that the severity of acute pancreatitis ultimately depends on the intensity of systemic inflammatory response $(22,35)$; the systemic response reflects on the severity of disease's manifestation (36). The disease pathophysiology is complex and includes multiple biochemical pathways with the initiating event usually being intraparenchymal pancreatic activation of proteolytic enzymes $(22,35)$. This usually occurs in the presence of bile and duodenal contents into the pancreatic duct system. Disease progression is based on the biochemical balance between secreted pro-inflammatory (i.e. TNF- $\alpha$, IL-1, IL-6, IL-8, PAF) and anti-inflammatory cytokines (i.e.IL-2, IL-10, IL-11) $(13,37,38)$. In the evolution of acute pancreatitis TNF- $\alpha$ plays a prominent role $(14,39)$. TNF- $\alpha$ has long been considered one of the initial triggers of the inflammatory cascade since it stimulates synthesis and release of multiple cytokines $(40,41)$. It regulates cell apoptosis via increased production of ICAM-1 (intercellular adhesion molecule-1), aggregation of pancreatic neutrophils and activation of factors such as MAP-kinase, NF-kB and PAP-1 (pancreas associated peptide-1) that comprise substantial factors in inflammation enhancement $(42,43)$. TNF- $\alpha$ levels have been correlated to morbidity and mortality associated with acute pancreatitis (23).

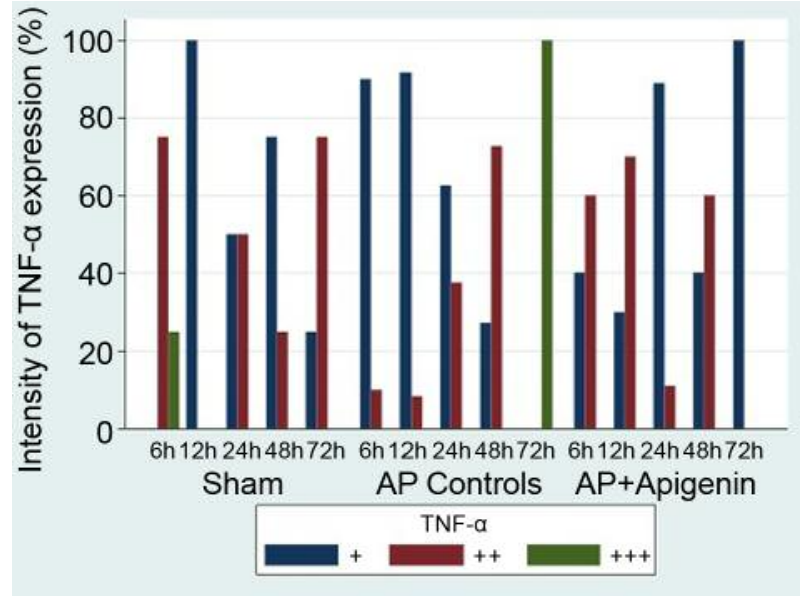

Figure 3. Intensity of TNF- $\alpha$ expression [mild (+), moderate $(+)$, intense $(+)]$ given as percentage for the three different groups (sham, control, apigenin) and each subgroup based on postoperative time. AP Controls $=$ Control group $($ Acute Pancreatitis $) ; A P+$ Apigenin $=$ Apigenin group (Acute Pancreatitis+Apigenin).

In the present study, we investigated whether apigenin has anti-inflammatory effects during an acute pancreatitis episode, thus reducing episode severity. To this direction the levels of TNF- $\alpha$ were examined in rat pancreas since apigenin has been shown to down-regulate TNF- $\alpha$ expression (4-6). 
in vivo $33: 1133-1141(2019)$

Table I. At postoperative time of 6, 12, 24, 48 and $72 \mathrm{~h}$, pancreatic TNF- $\alpha$ expression and histopathological characteristics of acute pancreatitis (hemorrhage, duct dilatation, edema, acinar necrosis, inflammatory infiltration) are presented for the Sham, Control and Apigenin Group. Level of statistical significance is at $p=0.05$. Kendall's rank correlation coefficient is given as "Kendall's tau".

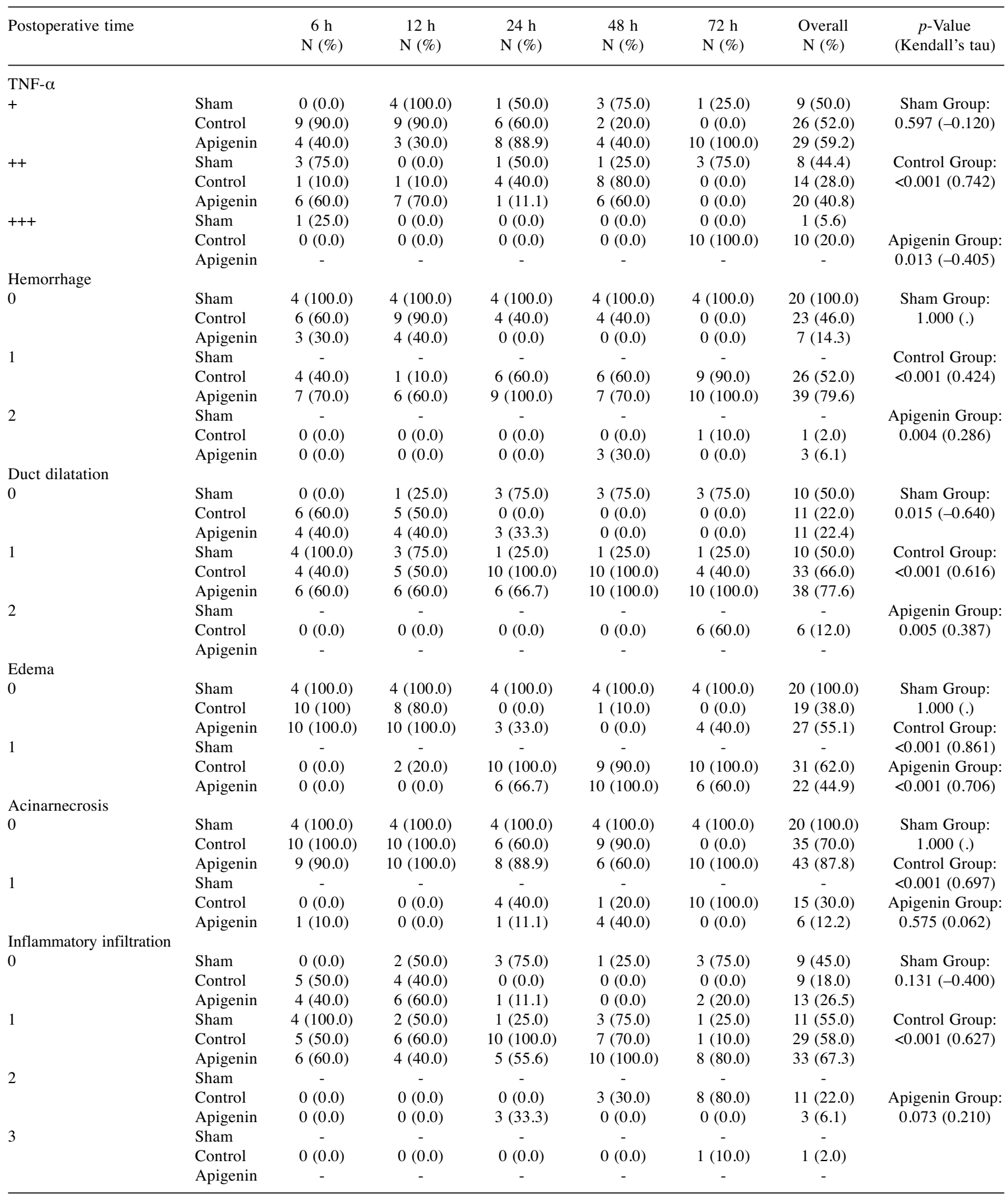

$+=$ mild TNF- $\alpha$ expression; ++=moderate TNF- $\alpha$ expression; $+++=$ intense TNF- $\alpha$ expression; $0=$ absence of lesions; $1=$ mild degree lesions; $2=$ moderate degree lesions; $3=$ severe degree lesions. 
Our histopathological evaluation indicated that pancreatitis was ranging from mild to severe necrotizing. In the sham group and as expected, a significant change in $\mathrm{TNF}-\alpha$ expression relative to postoperative time was not observed. Regarding the pathologic parameters studied, there was no significant difference apart from duct dilatation, where a small decremental tendency was observed. This is difficult to interpret as no pancreatitis was caused in this group. A possible explanation may be that the laparotomy itself provoked tissue stress reaction that the rat organism initially responded by increased pancreatic enzyme secretion and thus duct dilatation, which reduced with time progression and tissue stress resolution. In the control group, the immunohistochemical study revealed a significant difference in TNF- $\alpha$ expression in relation to postoperative time. Furthermore, at $6 \mathrm{~h}$ there was mild TNF- $\alpha$ expression in $90 \%$ of the animals, which progressively became moderate and finally intense in $100 \%$ of the animals at $72 \mathrm{~h}$. In addition, there was a significant difference in all pathologic parameters studied (haemmorhage, duct dilatation, edema, necrosis, inflammatory infiltration). In the apigenin group, there was a statistically significant decremental tendency of TNF- $\alpha$ expression in relation to postoperative time. Moreover, in this group no intense TNF- $\alpha$ expression was detected at any given postoperative time. At 6 $\mathrm{h}$ there was moderate TNF- $\alpha$ expression in $60 \%$ and mild in $40 \%$ of the animals that progressively and at $72 \mathrm{~h}$ reverted to mild in all animals (100\%).

Hence, with time progression TNF- $\alpha$ expression was becoming appreciably milder, which coupled with the absence of intense TNF- $\alpha$ expression, leads to the conclusion that apigenin has a beneficial role in disease progression. Moreover, in the AP group, there was a statistically significant difference regarding haemmorhage, duct dilatation and edema, but not regarding inflammatory infiltration. Among the study groups and as probably anticipated, a possible TNF- $\alpha$ expression difference most likely would become apparent at late postoperative times, when pathological changes and TNF- $\alpha$ expression would have been well established. From the analysis of pancreatic tissue parameters in each group and at $72 \mathrm{~h}$ postoperatively, it became evident that apigenin significantly reduced pancreatic TNF- $\alpha$ expression and severity of pancreatitis as reflected by the percentage of pancreatic necrosis. Our findings further support recent studies with similar results on the effects of apigenin in the pancreas $(28,44)$. In the last decade, further support for the beneficial role of flavones in pancreatitis has been provided by studies on the effects of scutellarin $(45,46)$.

To date the beneficial role of apigenin in acute pancreatitis has been shown only via a limited number of markers and indices $(28,44,47,48)$. TNF- $\alpha$ is strongly associated with acute pancreatitis as it has a pivotal role in the disease pathophysiology. Thus, the current study has further enhanced the hypothesis that apigenin has a beneficial role in acute pancreatitis. Further studies in pancreatitis, investigating more cytokines or other biochemical and/or tissue markers in association with apigenin are needed to establish the beneficial role of apigenin in acute pancreatitis.

\section{Conclusion}

This study investigated the anti-inflammatory effects of apigenin in an experimental model simulating obstructive gallstone pancreatitis. Pancreatic inflammatory response was reflected by tissue expression of the pro-inflammatory cytokine TNF- $\alpha$ coupled to histological evaluation of the pancreas. Our results indicated that apigenin slows progression and reduces severity of acute pancreatitis as expressed both by cytokine expression and histopathological changes. Apigenin may serve as an adjunct to a more successful therapeutic strategy in acute pancreatitis. As a result, apigenin administration to humans may have a therapeutic role in the management of acute pancreatitis. Additional and supplementary high-power studies are $a$ sine qua non in order to obtain safe results that will not only apply to experimental models, but will hopefully be translated to clinical application.

\section{Conflicts of Interest}

The Authors declare no conflicts of interest regarding this study.

\section{Authors' Contributions}

Alexandros Charalabopoulos: study conception, drafting of manuscript and analysis and interpretation of data; Spyridon Davakis: drafting of manuscript and analysis and interpretation of data; Maria Lambropoulou: analysis and interpretation of data; Apostolos Papalois: study conception and design; Constantinos Simopoulos: study conception and design; Alexandra Tsaroucha: study conception and design, acquisition of data and critical revision of manuscript.

\section{Acknowledgements}

The study was mainly supported by a research scholarship from the Experimental Research Center of 'ELPEN' that the Authors would like to thank.

\section{References}

1 Shankar E, Goel A, Gupta K and Gupta S: Plant flavone apigenin: An emerging anticancer agent. Curr Pharmacol Rep 3(6): 423-446, 2017. PMID: 29399439. DOI: 10.1007/s40495017-0113-2

2 Aggarwal BB, Vijayalekshmi RV and Sung B: Targeting inflammatory pathways for prevention and therapy of cancer: short-term friend, long-term foe. Clin Cancer Res 15: 425-430, 2009. PMID: 19147746. DOI: 10.1158/1078-0432.CCR-08-0149 
3 Woo ER, Pokharel YR, Yang JW, Lee SY and Kang KW: Inhibition of nuclear factor-kappa B activation by 2',8"-bi apigenin. Biol Pharm Bull 29: 976-980, 2006. PMID: 16651730.

4 Kowalski J, Samojedny A, Paul M, Pietsz G and Wilczok T: Effect of apigenin, kaempferol and resveratrol on the expression of interleukin-1beta and tumor necrosis factor-alpha genesin J774.2 macrophages. Pharmacol Rep 57: 390-394, 2005. PMID: 15985724.

5 Xu C, Shen G, Chen C, Gelinas C and Kong AN: Suppression of NF-kappa B and NF-kappa B-regulated gene expression by sulforaphane and PEITC through I kappa B alpha, IKK pathway in human prostate cancer PC-3 cells. Oncogene 24: 4486-4495, 2005. PMID: 15856023. DOI: 10.1038/sj.onc.1208656

6 Seo HS, Sikder MA, Lee HJ, Ryu J and Lee CJ: Apigenin inhibits Tumor Necrosis Factor- $\alpha$-induced production and gene expression of mucin through regulating Nuclear Factor-Kappa B signaling pathway in airway epithelial cells. Biomol Ther 22(6): 525-531, 2014. PMID: 25489420. DOI: 10.4062/biomolther. 2014.094

7 Bradley EL 3rd: A clinically based classification system for acute pancreatitis. Arch Surg 128(5): 586-590, 1993. PMID: 8489394.

8 Pal KM, Kasi PM, Tayyeb M, Mosharraf SM and Fatmi Z: Correlates of morbidity and mortality in severe necrotizing pancreatitis. ISRN Surg 2012: 215193, 2012. PMID: 22844617. DOI: $10.5402 / 2012 / 215193$

9 Pezzilli R, Morselli-Labate AM, Campana D, Casadei R, Brocchi E and Corinaldesi R: Evaluation of patient-reported outcome in subjects treated medically for acute pancreatitis: a follow-up study. Pancreatology 9(4): 375-382, 2009. PMID: 19451747. DOI: $10.1159 / 000181171$

10 Sarr MG, Nagorney DM, Mucha P Jr., Farnell MB and Johnson $\mathrm{CD}$ : Acute necrotizing pancreatitis: Management by planned, staged pancreatic necrosectomy/debridement and delayed primary wound closure over drains. Br J Surg 78(5): 576-581, 1991. PMID: 2059810

11 Tsiotos GG, Luque-de Leon E and Sarr MG: Long-term outcome of necrotizing pancreatitis treated by necrosectomy. Br J Surg 85(12): 1650-1653, 1998. PMID: 9876068. DOI: 10.1046/ j.1365-2168.1998.00950.x

12 Bhatia M: Novel therapeutic targets for acute pancreatitis and associated multiple organ dysfunction syndrome. Curr Drug Targets Inflamm Allergy 1: 343, 2002. PMID: 14561181.

13 Nagel S, Ehrentraut S, Meyer C, Kaufmann M, Drexler HG and MacLeod RA: NFkB is activated by multiple mechanisms in hairy cell leukemia. Genes Chromosomes Cancer 54(7): 418432, 2015. PMID: 25960206. DOI: $10.1002 / \mathrm{gcc} .22253$

14 Coelho AM, Kunitake TA, Machado MC, Martins JO, Patzina RA, D'Albuquerque LA and Jukemura J: Is there a therapeutic window for pentoxifylline after the onset of acute pancreatitis? Acta Cir Bras 27(7): 487-493, 2012. PMID: 22760835.

15 Habtezion A: Inflammation in acute and chronic pancreatitis. Curr Opin Gastroenterol 31(5): 395-399, 2015. PMID: 261 07390. DOI: $10.1097 /$ MOG.0000000000000195

16 Bhatia M: Inflammatory response on the pancreatic acinar cell injury. Scand J Surg 94: 97-102, 2005. PMID: 16111089. DOI: $10.1177 / 145749690509400203$

17 Hong YP, Chen C, Guo WY, Zhao L, Mei FC, Xiang MW and Wang WX: Effects of castanospermine on inflammatory response in a rat model of experimental severe acute pancreatitis.
Arch Med Res 47(6): 436-445, 2016. PMID: 27986123. DOI: 10.1016/j.arcmed.2016.11.007

18 Bishehsari F, Sharma A, Stello K, Toth C, O'Connell MR, Evans AC, La Rusch J Muddana V, Papachristou GI and Whitcomb DC: TNF-alpha gene (TNFA) variants increase risk for multiorgan dysfunction syndrome (MODS) in acute pancreatitis. Pancreatology 12(2): 113-118, 2012. PMID: 22487520. DOI: 10.1016/j.pan.2012.02.014

19 Denham W, Yang J and Fink G: Gene targeting demonstrates additive detrimental effects of interleukin-1 and tumor necrosis factor during pancreatitis. Gastroenterology 113: 1741-1746, 1997. PMID: 9352880.

20 Hughes CB, Grewal HP, Gaber LW, Kotb M, El-din AB, Mann $\mathrm{L}$ and Gaber AO: Anti-TNF alpha therapy improves survival and ameliorates the pathophysiologic sequelae in acute pancreatitis in the rat. Am J Surg 171: 274-280, 1996. PMID: 8619467.

21 Kim N, Park JM, Lee SH, Kim BH, Son JH, Ryu JK, Kim YT and Lee W: Effect of combinatory treatment with resveratrol and guggulsterone on mild acute pancreatitis in mice. Pancreas 46(3): 366-371, 2017. PMID: 28099255. DOI: 10.1097/MPA.00 00000000000763

22 Li WD, Jia L, Ou Y, Jiang SM, Qiu JH, Huang YX and Du H: Infliximab: protective effect to intestinal barrier function of rat with acute necrosis pancreatitis at early stage. Pancreas 42(2): 366-367, 2013. PMID: 23407490. DOI: 10.1097/MPA. 0b013 e31825c5273

23 Basselink MG, van Snatvoort HC, Wittemen BJ and Gooszen HG: Dutch Acute Pancreatitis Study Group. Management of severe acute pancreatitis: it's all about timing. Curr Opin Crit Care 13(2): 200-206, 2007. PMID: 17327743. DOI: 10.1097/ MCC.0b013e328015b8af

24 Aydin S, Isik AT, Unal B, Comert B, Ozyurt M, Deveci S, Ozgur G, Cengiz O, Tasci I and Mas MR: Effects of infliximab on bacterial translocation in experimental acute necrotizing pancreatitis. Indian J Med Res 135(5): 656-661, 2012. PMID: 22771595.

25 Yildiz B and Hamaloglu E: Basic Experimental pancreatitis models for beginners. Surg Sci 1: 31-39, 2010. DOI: 10.4236/ ss.2010.12007

26 Basios N, Lampropoulos P, Papalois A, Lambropoulou M, Pitiakoudis MK, KotiniA, Simopoulos C and Tsaroucha AK: Apigenin attenuates inflammation in experimentally induced acute pancreatitis-associated lung injury. J Invest Surg 29(3): 121-127, 2016. PMID: 26631908. DOI: 10.3109/08941 939. 2015.1088603

27 Abreu FF, Souza AC, Teixeira SA, Soares AG, Teixeira DF, Soares RC, Santana MT, Lauton Santos S, Costa SK, Muscará MN and Camargo EA: Elucidating the role of oxidative stress in the therapeutic effect of rutin on experimental acute pancreatitis. Free Radic Res 50(12): 1350-1360, 2016. PMID: 27733068. DOI: $10.1080 / 10715762.2016 .1247494$

28 Lampropoulos P, Lambropoulou M, Papalois A, Basios N, Manousi M, Simopoulos C and Tsaroucha AK: The role of apigenin in an experimental model of acute pancreatitis. J Surg Res 183(1): 129-137, 2013. PMID: 23273883. DOI: 10.1016/ j.jss.2012.11.053

29 Gradolatto A, Basly JP, Berges R, Teyssier C, Chagnon MC, Siess MH and Canivenc-Lavier MC: Pharmacokinetics and metabolism of apigenin in female and male rats after a single oral administration. Drug Metab Dispos 33(1): 49-54, 2005. PMID: 15466493. DOI: 10.1124/dmd.104.000893 
30 Mullie P, Clarys P, Deriemaeker $\mathrm{P}$ and Hebbelinck M: Estimation of daily human intake of food flavonoids. Plant Foods Hum Nutr 62(3): 93-98, 2007. PMID: 17597415. DOI: 10.1007/s11130-007-0047-7

31 Zausinger S, Baethmann A and Schmid-Elsaesser R: Anesthetic methods in rats determine outcome after experimental focal cerebral ischemia: mechanical ventilation is required to obtain controlled experimental conditions. Brain Res Brain Res Protoc 9(2): 112-121, 2002. PMID: 12034330.

32 Sidhu S, Pandhi P, Malhotra S, Vaiphei K and Khanduja KL: Melatonin treatment is beneficial in pancreatic repair process after experimental acute pancreatitis. Eur J Pharmacol 628: 282, 2010. PMID: 19958759. DOI: 10.1016/j.ejphar.2009.11.058

33 Lambropoulou M, Papadopoulos N, Tripsianis G, Alexiadis G, Pagonopoulou O, Kiziridou A, Liberis V, Kakolyris S and Chatzaki E: Co-expression of survivin, c-erbB2, and cyclooxygenase-2 (COX-2): prognostic value and survival of endometrial cancer patients. J Cancer Res Clin Oncol 136: 427, 2010. PMID: 19756737. DOI: 10.1007/s00432-009-0673-6

34 Schulz KF and Grimes DA: Generation of allocation sequences in randomised trials: chance, not choice. Lancet 359: 515, 2002. PMID: 11853818. DOI: 10.1016/S0140-6736(02)07683-3

35 Sharma D, Jakkampudi A, Reddy R, Reddy PB, Patil A, Murthy HVV, Rao G5, Reddy DN and Talukdar R: association of systemic inflammatory and anti-inflammatory responses with adverse outcomes in acute pancreatitis: preliminary results of an ongoing study. Dig Dis Sci 62(12): 3468-3478, 2017. PMID: 29080144. DOI: $10.1007 / \mathrm{s} 10620-017-4813-6$

36 Wilson $\mathrm{J}$ and Zarabi S: BET 1: SIRS criteria as a way of predicting mortality in acute pancreatitis Emerg Med J 34: 621622, 2017. PMID: 28827292. DOI: 10.1136/emermed-2017207038.1

37 Pendharkar SA, Singh RG, Chand SK, Cervantes A and Petrov MS: Pro-inflammatory cytokines after an episode of acute pancreatitis: associations with fasting gut hormone profile. Inflamm Res 67(4): 339-350, 2018. PMID: 29288273. DOI: 10.1007/s00011-017-1125-4

38 Samanta J, Singh S, Arora S, Muktesh G, Aggarwal A, Dhaka N, Kant Sinha S, Gupta V, Sharma V and Kochhar R: Cytokine profile in prediction of acute lung injury in patients with acute pancreatitis. Pancreatology 18(8): 878-884, 2018. PMID: 30361069. DOI: $10.1016 /$ j.pan.2018.10.006

39 Habtezion A: Inflammation in acute and chronic pancreatitis Curr Opin Gastroenterol 31(5): 395-399, 2015. PMID: 26107390. DOI: 10.1097/MOG.0000000000000195
40 Surbatovic M and Radakovic S: Tumor necrosis factor- $\alpha$ levels early in severe acute pancreatitis: is there predictive value regarding severity and outcome? J Clin Gastroenterol 47(7): 637-643, 2013. PMID: 23470643. DOI: 10.1097/ MCG.0b013 e31828a6cfc

41 Norman J: The role of cytokines in the pathogenesis of acute pancreatitis. Am J Surg 175: 76-83, 1998. PMID: 9445247.

42 Gukovsky I, Gukovskaya AS, Blinman TA, Zaninovic V and Pandol SJ: Early NF-kB activation is associated with hormoneinduced pancreatitis. Am J Physiol 275: 1402-1414, 1998. PMID: 9843778. DOI: 10.1152/ajpgi.1998.275.6.G1402

43 Chen CC, Wang SS, Lu RH, Lu CC, Chang FY and Lee SD: Early changes of serum proinflammatory and anti-inflammatory cytokines after endoscopic retrograde cholangiopancreatography. Pancreas 26: 375-380, 2003. PMID: 12717271.

44 Mrazek AA, Porro LJ, Bhatia V, Falzon M, Spratt H, Zhou J, Chao $\mathrm{C}$ and Hellmich MR: Apigenin inhibits pancreatic stellate cell activity in pancreatitis. J Surg Res 196(1): 8-16, 2015. PMID: 25799526. DOI: 10.1016/j.jss.2015.02.032

45 Hanqing $\mathrm{C}$, Xiping $\mathrm{Z}$, Jingmin $\mathrm{O}$, Jun $\mathrm{J}$ and Dijiong W: Research on scutellarin parenteral solution's protective effects in rats with severe acute pancreatitis and multiple organ injuries. Inflammation 35(3): 1005-1014, 2012. PMID: 22105928. DOI: 10.1007/s 10753-011-9404-7

46 Kahraman A, Vurmaz A, Koca HB, Uyar H, Çat A, Tokyo C, Polat $\mathrm{C}$ and Köken T: The effect of quercetin on ceruleininduced acute pancreatitis. Medical Express (São Paulo, online) 4: 5, 2017. DOI: 10.5935/medicalexpress.2017.05.02

47 Chen H, Mrazek AA, Wang X, Ding C, Ding Y, Porro LJ, Liu $\mathrm{H}$, Chao C, Hellmich MR and Zhou J: Design, synthesis, and characterization of novel apigenin analogues that suppress pancreatic stellate cell proliferation in vitro and associated pancreatic fibrosis in vivo. Bioorg Med Chem 22(13): 33933404, 2014. PMID: 24837156. DOI: 10.1016/j.bmc.2014.04.043

$48 \mathrm{Li} \mathrm{KC}$, Ho YL, Hsieh WT, Huang SS, Chang YS and Huang GJ: Apigenin-7-glycoside prevents LPS-induced acute lung injury via downregulation of oxidative enzyme expression and protein activation through inhibition of MAPK phosphorylation. Int J Mol Sci 161: 1736-1754, 2015. PMID: 25590301. DOI: 10.3 390/ijms16011736

Received April 20, 2019

Revised June 6, 2019

Accepted June 10, 2019 